Thorax, 1980, 35, 536-542

\title{
Haemodynamic effects of terbutaline in chronic obstructive airways disease
}

\author{
G $J$ J TEULE AND P A MAJID
}

From the Departments of Internal Medicine and Cardiology, Free University Hospital, Amsterdam, The Netherlands

ABSTRACT Terbutaline, a cardioselective beta-adrenoceptor agonist, administered intravenously $\mathscr{O}_{-}$ $(250 \mu \mathrm{g})$ to seven patients with chronic obstructive airways disease (mean $\left.\mathrm{FEV}_{1} 0.99 \mathrm{l}\right)$ resulted in $\mathcal{J}_{\mathcal{O}}$ reduction of mean pulmonary artery pressure (resting $23 \pm 2$ to $19 \pm 2 \mathrm{mmHg}, \mathrm{p}<0.05$; exercise $43 \pm 3$ to $35 \pm 3 \mathrm{mmHg}, \mathrm{p}<0.05$ ) and calculated pulmonary vascular resistance (resting $168 \pm 27$ to $109 \pm 17$ dyne s cm ${ }^{-5}, \mathrm{p}<0.01$; exercise $170 \pm 30$ to $119 \pm 18$ dyne $\left.\mathrm{s} \mathrm{cm}^{-5}, \mathrm{p}<0.01\right)$ accompanied by an increase in heart rate (resting $86 \pm 5$ to $96 \pm 4$ per min, p $<0.01$; exercise $108 \pm 2$ to $114 \pm 2$ per min, $\mathrm{p}<0.01$ ) and cardiac output (resting $3.7 \pm 0.4$ to $4.1 \pm 0.4, p<0.05$; exercise $4.9 \pm 0.06$ to $\vec{\oplus}$ $\left.6 \cdot 1 \pm 61, \mathrm{~min}^{-1} \mathrm{~m}^{-2}, \mathrm{p}<0.05\right)$. The haemodynamic changes were associated with an increase in resting peak expiratory flow rate $(184 \pm 20$ to $216 \pm 251 / \mathrm{min}, \mathrm{p}<0.01)$, while the calculated indices of ventilation/perfusion relationship remained essentially unchanged. The reduction in mean pulmonary artery pressure after terbutaline observed in the present studies was probably the result $\frac{}{0}$ of a combination of simple vasodilator effect, the reduction in airways resistance, and increase in the ventilation.

The precise mechanism by which chronic increase in airways resistance leads to pulmonary hypertension in some patients is still controversial. At present the evidence favours a multifactorial aetiology in which chronic hypoxaemia probably has a dominant role to play. ${ }^{12}$ Although sympathomimetic amines are traditionally employed as bronchodilators, ${ }^{3}$ selective $\boldsymbol{\beta}_{2}$-adrenoceptor agonists such as terbutaline may also have beneficial effects on pulmonary vascular dynamics in chronic obstructive airways disease (COAD). Studies at rest have demonstrated that these drugs reduce pulmonary vascular resistance. ${ }^{45}$ However, their unfavourable effect on the ventilation/perfusion relationship, resulting in reduced systemic arterial oxygen tension in some patients, has been a cause for concern. ${ }^{6}$

Patients with COAD who are in a stable clinical state usually develop symptoms only on exercise. Studies performed solely at rest provide little information about changes occurring in the pulmonary circulation and gas transport during stress. The following study was, therefore, undertaken to evaluate the cardiorespiratory effects of

Address for reprint requests: Dr PA Majid, Department of Cardiology Toronto General Hospital, Toronto, Ontario MSG 1L7, Canada. terbutaline at rest and on exercise in a group of patients with moderately severe COAD.

\section{Methods}

Seven male patients, average age 63 years (range 3 . 51-79 yr), average height $173 \mathrm{~cm}$ (range 168$186 \mathrm{~cm}$ ), average weight $71 \mathrm{~kg}$ (range $62-85 \mathrm{~kg}$ ) with stable, moderately severe COAD of betweeno eight and 15 years' duration took part in the study (table 1). None of the patients had as history of angina pectoris, myocardial infarction established hypertension, or any other hearo disease. The studies were carried out after propen informed consent had been obtained.

Table 1 Results of pulmonary function studies

\begin{tabular}{|c|c|c|c|c|}
\hline Patient & $T L C(l)$ & $R V(l)$ & $F E V_{1}(l)$ & $F E V_{1} / V C(\%)$ \\
\hline 1 & $8 \cdot 13$ & $4 \cdot 75$ & $1 \cdot 03$ & 44 \\
\hline 2 & $8 \cdot 35$ & $4 \cdot 13$ & $1 \cdot 47$ & 40 \\
\hline 3 & 6.90 & $4 \cdot 18$ & 0.82 & 34 \\
\hline 4 & $5 \cdot 02$ & 1.65 & 1.03 & 43 \\
\hline 5 & $6 \cdot 76$ & $3 \cdot 28$ & 0.62 & 26 \\
\hline 6 & 7.01 & $3 \cdot 84$ & 0.97 & 37 \\
\hline 7 & $5 \cdot 25$ & 3.08 & 0.09 & 41 \\
\hline
\end{tabular}

TLC = total lung capacity; $R V=$ residual volume; $F E V_{1}=$ force expiratory volume in one second; $\mathrm{VC}=$ vital capacity. 
The resting electrocardiogram was normal in every patient. Each patient walked on a treadmill to exclude the possibility of ischaemic changes on the electrocardiogram. Chest radiographs showed normal heart configuration and cardiothoracic ratio less than $50 \%$ in all patients. Routine haematology, biochemistry, liver function, and renal function tests were within normal range in all patients.

\section{DESIGN OF INVESTIGATION}

All the patients were acquainted with the laboratory staff and the surroundings beforehand. Each patient was trained to exercise in the supine position on a bicycle ergometer at a constant speed and at a level which he could perform comfortably for six minutes.

On the day of the investigation the patients were studied in postabsorptive state, without any premedication. Drugs or aerosols likely to influence the results were withheld for 12 hours before the study.

Fifteen to 20 minutes after insertion of catheters, cardiac output was measured at rest for four minutes, followed by a six minute period of supine leg exercise at a predetermined speed and load. Cardiac output was measured during the fifth and sixth minutes of exercise. The electrocardiogram was monitored continuously and recorded from an adhesive disc electrode applied to V5 position. Systemic arterial, pulmonary arterial, and wedge pressures were recorded simultaneously. Approximately 20 minutes later, when all the haemodynamic parameters had reached the control state, terbutaline $250 \mu \mathrm{g}$ in $10 \mathrm{ml}$ of normal saline was injected into the pulmonary artery catheter over a period of three minutes. The patient then rested for 20 minutes, after which cardiac output was again measured together with the recording of intravascular pressures and the electrocardiogram. The second period of exercise was then begun at the same speed and work load as previously, lasting again for six minutes.

\section{LABORATORY TECHNIQUES}

Pulmonary arterial and wedge pressures were recorded through a double lumen $9 \mathrm{~F}$ catheter inserted into one of the medial antecubital veins. The systemic arterial pressure was measured at the aortic root by percutaneous introduction of a nylon catheter $(75 \times 1.5 \mathrm{~mm})$ into the brachial artery by modified Seldinger technique. The common zero level for all the pressures was at the midchest level. The pressures were transduced through HP $1280 \mathrm{C}$ strain-gauge manometers and recorded on a 6-channel direct-writing recorder (Siemens Mingograph 800 EMT 8B). All the manometers were electronically calibrated before and after each period of test, the calibration being checked frequently against an open column of saline.

Cardiac output was measured by the direct Fick method. Two systemic arterial blood samples and three mixed venous samples were taken during each cardiac output estimation. Expired air was collected and respiratory rate and ventilatory volumes were measured in a Tissot spirometer. Carbon dioxide concentration in the expired air was analysed by Godart's Capnograph previously calibrated by gases of known concentration. The oxygen concentration was measured by Servomex (OA 272). Using these methods, under similar conditions of study to those of present investigations, duplicate measurement of cardiac output agreed to within $8 \%$ both at rest and on exercise.

Peak expiratory flow rate was measured in triplicate at rest only, by a mini Wright's peak flow meter. The coefficient of variation of the PEFR with this instrument was calculated from triplicate readings taken from 10 volunteers and was found to be $1 \%$.

MEASUREMENTS, CALCULATIONS, AND STATISTICAL ANALYSIS

Phasic pressure measurements were averaged over two complete respiratory cycles. Mean pressures were measured by electronic integration. Systemic and pulmonary vascular resistances were calculated according to known formulae. ${ }^{7}$ Venous admixture was estimated from the shunt equation using the calculated ideal alveolar oxygen tension. ${ }^{8}$ Heart rate was measured from five electrocardiographic complexes. The probability of significance of changes between paired samples was determined by Student's $t$ test.

\section{Results}

The injection of terbutaline in the pulmonary artery did not cause any untoward symptoms. The heart rate, intravascular pressures, and electrocardiogram did not show any immediate changes.

EFFECT ON HEART RATE, OXYGEN UPTAKE, CARDIAC OUTPUT, AND STROKE VOLUME (FIG 1) As compared to the control study a significant increase in heart rate was observed both at rest $(p<0.01)$ and on exercise $(p<0.01)$. Cardiac output was normal in all the patients at rest and 


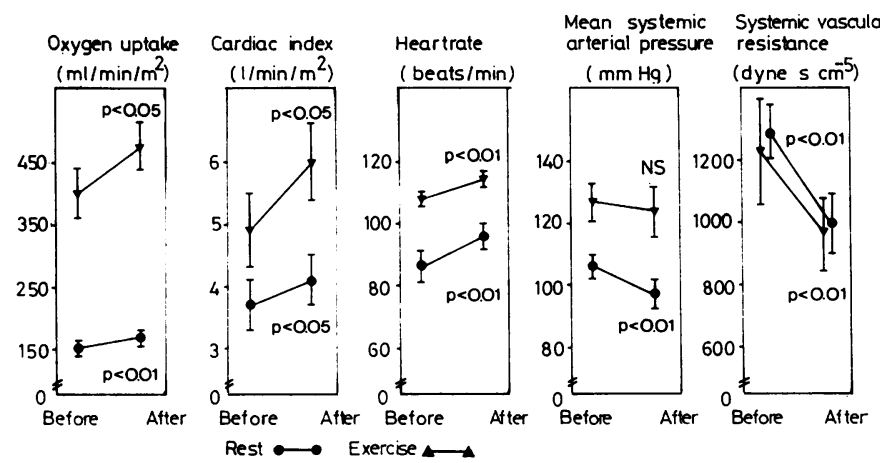

Fig 1 Haemodynamic effects of terbutaline in patients with chronic obstructive airways disease. Conversion to SI units; $1 \mathrm{mmHg}=0 \cdot 133 \mathrm{kPa}$. the response to a twofold increase in oxygen uptake $(400 \pm 39 \mathrm{ml} / \mathrm{min})$ during exercise was adequate. After terbutaline a significant increase in cardiac output was demonstrated both at rest $(p<0.05)$ and on exercise $(p<0.05)$, but this was achieved mainly by an increase in oxygen uptake $(p<0.01, p<0.05)$. Stroke volume was unchanged at rest, but there was a small yet significant increase observed on exercise $(p<0.05)$.

\section{EFFECTS ON PULMONARY ARTERIAL AND}

WEDGE PRESSURES AND PULMONARY

VASCULAR RESISTANCE (FIG 2)

The pulmonary artery pressure, phasic as well as the mean, was marginally raised at rest; however, there was a steep rise on exercise disproportionate to the level at which the patients exercised. Pulmonary wedge pressure was normal at rest, but once again an abnormal rise was observed during exercise. After terbutaline the pulmonary arterial pressure fell significantly $(\mathrm{p}<0.05)$ at rest, on exercise a significant decrease in the wedge $(\mathrm{p}<0.05)$ and pulmonary arterial pressure $(p<0.05)$ was observed. Commensurate with the decline in the pressures in the pulmonary circu-o lation, a highly significant decrease in pulmonary? vascular resistance, total as well as arteriolar, was demonstrated at rest $(\mathrm{p}<0.01$ and $\mathrm{p}<0.01)$ as well as during exercise $(\mathrm{p}<0.01, \mathrm{p}<0.05)$.

EFFECTS ON SYSTEMIC ARTERIAL PRESSURE AND VASCULAR RESISTANCE (FIG 1)

Systemic arterial pressure was normal at rest and averaged $106 \pm 4 \mathrm{mmHg}(14 \cdot 1 \pm 0.53 \mathrm{kPa})$. Aftē̄ the drug a significant reduction in the mearo arterial pressure was observed at rest, while $i[$ remained unchanged on exercise. A highl $\overrightarrow{5}$ significant reduction in the calculated systemic vascular resistance was demonstrated at res? $(p<0.01)$ as well as on exercise $(p<0.01)$.

EFFECTS ON PEAK EXPIRATORY FLOW RATE, ARTEO RIAL BLOOD GAS TENSIONS, VENOUS ADMIXTURE PHYSIOLOGICAL DEAD SPACE, MINUTE VENTILATIONO AND ALVEOLAR VENTILATION (TABLE 2, FIG 3)

Peak expiratory flow rate (PEFR) was measure@ only at rest and averaged $184 \pm 201 / \mathrm{min}$. Intraß venous terbutaline produced a significant bu甲

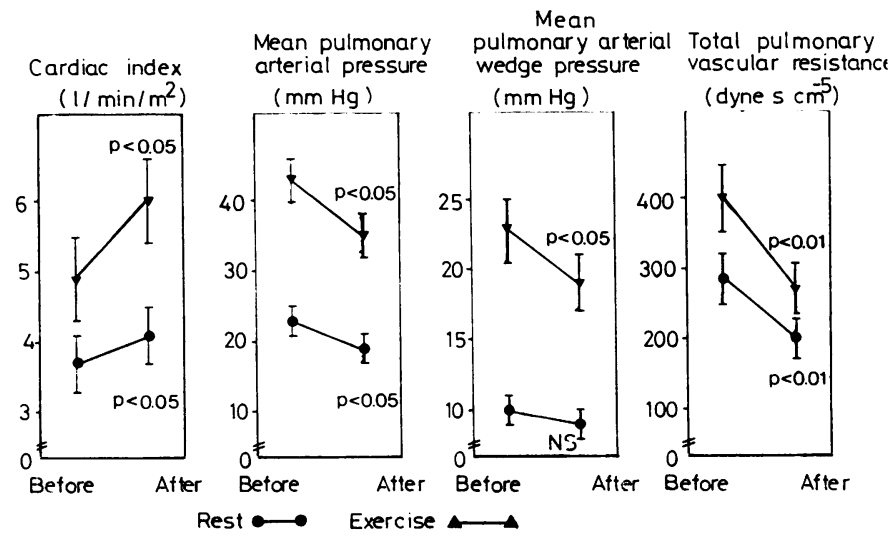

Fig 2 Effect of terbutaline on pulmonary circulation in patients with chronic obstructive airways disease. Conversion to SI units as in fig 1 . 
Table 2 Effect of terbutaline on arterial blood gas tensions and hydrogen ion concentration in patients with chronic obstructive airways disease, at rest and on exercise

\begin{tabular}{|c|c|c|c|c|}
\hline & \multicolumn{2}{|l|}{ Rest } & \multicolumn{2}{|l|}{ Exercise } \\
\hline & Control & Terbutaline & Control & Terbutaline \\
\hline $\begin{array}{l}\mathrm{pH} \\
\mathrm{PaCO}_{2}(\mathrm{mmHg}) \\
\mathrm{PaO}_{2}(\mathrm{mmHg}) \\
\mathrm{SaO}_{2}(\%)\end{array}$ & 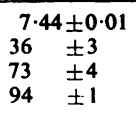 & $\begin{aligned} & 7.45 \\
37 & \pm 0.01 \\
37 & \pm 3 \\
+68 & \pm 3 \\
94 & \pm 1\end{aligned}$ & 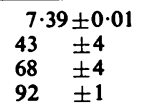 & $\begin{array}{cl}* 7 \cdot 41 & \pm 0.01 \\
* 39 & \pm 3 \\
68 & \pm 4 \\
93 & \pm 1\end{array}$ \\
\hline
\end{tabular}

Data expressed as mean $\pm \mathrm{SE}$ of mean. Probabilities of significance of difference between paired data: ${ }^{*} p<0 \cdot 05,+p<0.01$. Conversion to SI units: $1 \mathrm{mmHg}=0.133 \mathrm{kPa}$.

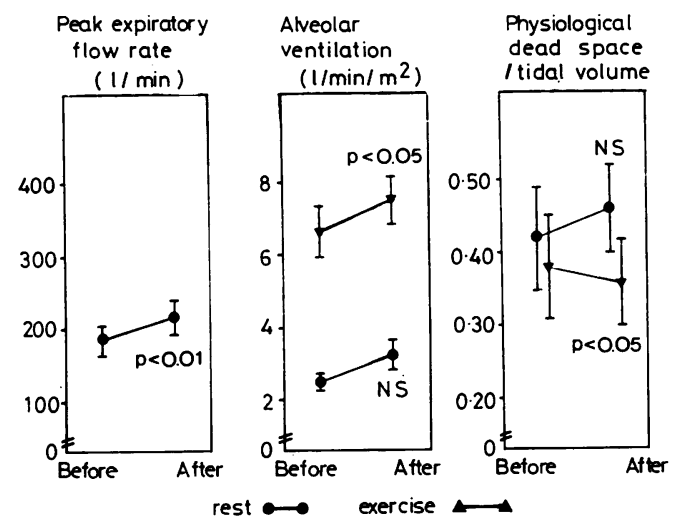

small increase in PEFR $(\mathrm{p}<0.01)$. The arterial blood oxygen tension $\left(\mathrm{PaO}_{2}\right)$ and saturation was normal at rest and on exercise. After terbutaline there was a slight but significant fall in $\mathrm{PaO}_{2}$ at rest but the saturation remained within normal limits. Venous admixture and physiological dead space were not altered after terbutaline. Minute ventilation and alveolar ventilation increased only significantly during exercise.

\section{Discussion}

Pulmonary hypertension in chronic obstructive airways disease is distinguished by its labile nature and a propensity to become rapidly worse on stress, which might be induced by infection, hypoxia, or exercise. ${ }^{2}$ It is desirable to employ some form of stress in examining the effects of acute interventions, especially if the patients are in a stable clinical state and show minimal abnormalities at rest. For purposes of convenience we used supine leg exercise to study the effects of terbutaline, a selective beta-adrenergic agonist, in a group of patients with moderately severe obstructive pulmonary disease. The results were clear-cut. During the control study, a marginally raised pulmonary artery pressure at rest increased inappropriately in relation to the augmen-

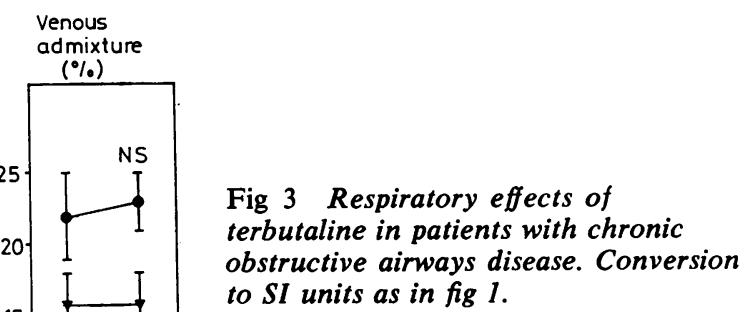

tation of the flow during exercise. The calculated pulmonary vascular resistance was raised at rest and remained unchanged during exercise. The pulmonary wedge pressure which was within the normal range at rest, rose abnormally on exercise. One of the consistent features of pulmonary hypertension in chronic bronchitis is that the pulmonary artery diastolic pressure exceeds wedge pressure at all levels. The diastolic pressure gradient is acutely sensitive to changes in the blood oxygen saturation, hydrogen ion concentration, and exercise. ${ }^{19}$ In the present series a diastolic pressure gradient was demonstrable in all patients at rest. As expected, this pressure difference became wider on exercise.

In order to place these findings in proper perspective it is important to emphasise the factors in the design of the study which limit their reliability. Practical difficulties involved in the measurement of changes in pulmonary arterial pressure at rest derive mainly from the low pressures normally seen in the pulmonary circulation. Large alterations in vascular resistance may be associated with little (or no) change in the pressure. Moreover the known observation that the pulmonary artery pressure gradually declines during cardiac catheterisation may lead to extra difficulties in analysing the effects of any drug 
intervention. Nevertheless the limitations imposed by the small arteriovenous differences in pressure in the normal lung may not be applicable to patients with pulmonary hypertension. The increased pulmonary vascular resistance probably provides a more sensitive situation for testing drugs particularly with a vasodilator action. ${ }^{2}$ Furthermore simultaneous measurement of changes in the pulmonary blood flow make the demonstration of a vasodilatory effect considerably easier. The problem could, of course, be circumvented by alternating control and experimental observations. The prolonged duration of action of terbutaline and the ethical considerations involved in two separate intravascular studies precluded a reversal of the order of control and test situations. On the other hand the reproducibility of the objective measurements was determined carefully beforehand. The results from the control and test situations may, therefore, be compared with reasonable confidence.

The significance of changes observed in pulmonary artery pressure during exercise also requires critical consideration. In normal subjects mean pulmonary artery pressure increases and remains high until approximately the seventh minute after which there is a gradual decline without any large alteration in the flow. ${ }^{10}$ Although the effects of prolonged exercise on pulmonary artery pressure in patients with chronic bronchitis are not known, we have restricted our exercise studies to the first six minutes only. Furthermore, measurement of pulmonary artery pressure is incomplete without simultaneous measurement of pulmonary wedge pressure or the left atrial pressure. Large numbers of studies have confirmed that pulmonary wedge pressure or the left atrial pressure contributes substantially to the increase in pulmonary arterial pressure on exercise in patients with chronic bronchitis. ${ }^{9}$ Increased pulmonary wedge pressure during exercise was likewise demonstrated in the group of patients studied by us. In an effort to explain the abnormal increase in wedge pressure Harris and his colleagues ${ }^{11}$ have emphasised the role of increased intrathoracic pressure which might be responsible by analogy to the observatons made in patients with COAD during voluntary hyperventilation. Lockhart et al, ${ }^{9}$ however, failed to demonstrate any significant increase in simultaneously measured oesophageal pressure during supine leg exercise in patients with COAD. The possibility that increased wedge pressure may reflect events in the left ventricle has also intrigued physiologists and clinicians alike. Present evidence is inconclusive about the status of the left ventricle in chronic pulmonar disease despite the use of sophisticated techniques in the study of left ventricular function. ${ }^{12} \frac{18}{0}$ Finally, disease of the left ventricle may be rese ponsible for an increase in wedge pressure evero if meticulous care has been taken to exclude common causes on clinical grounds.

The mechanism by which terbutaline reduce $\vec{\phi}$ pulmonary artery pressure is purely speculative A significant reduction in the arteriovenous pres sure difference in face of a considerable rise flow suggests an appreciable increase in the pul monary vascular capacitance. Although we diọ not measure central blood volume in the present study, collateral evidence from studies with theू beta-receptor agonist isoprenaline in patients with COAD indicate that the reduction in pul? monary vascular resistance is accompanied by an increase in the pulmonary blood volume. ${ }^{14}$

A simple vasodilatory effect is probably com $-\overrightarrow{0}$ pounded by the significant changes observed ino the airways resistance and ventilation. Harris et $a l^{11}$ suggested that the high alveolar and in trathoracic pressure compresses resistance vessels in the lung leading to an increase in pulmonaryo artery pressure. The increase in pulmonary vas: cular resistance, without any change in blood gas tensions which is observed after voluntary hyper $\overrightarrow{0}$ ventilation or exercise lends support to this view 3

Accordingly, the reduction of pulmonary vas? cular resistance after a drug such as terbutaline could be explained partially by its direct dilatory action on the bronchi.

It is difficult to assess the part played by the increased ventilation observed after the drug ing reducing pulmonary arterial pressure. An appar ent reduction as a result of an increase in theo mid-thoracic diameter could reasonably be dis 3 counted because increased ventilation observedo after exercise or voluntary hyperventilation at approximately similar flow as demonstrated aftero the drug leads to opposite changes in the pul-n monary artery pressure. Hypoxia after underventilation in chronic bronchitis had been $\tilde{S}^{\circ}$ regarded traditionally as the major factor in the genesis of pulmonary hypertension. ${ }^{1}$ However our group of patients had normal arterial bloodo oxygen saturation at rest as well as on exercise. $\bar{\Phi}$ The suggestion that increased ventilation after ${ }^{\text {? }}$ terbutaline may produce improvement in seg- $\square$ mental hypoxia leading to reduction in pulmonary arterial pressure ${ }^{15}$ cannot be discounted by the present study.

The changes in systemic circulation producedo by terbutaline are compatible with beta-adrenergic receptor stimulation both centrally and in 
the peripheral vasculature. Since the studies were performed in the supine position, one would expect less reflex response from the peripheral adrenergic activity. Significant increase in heart rate, cardiac/stroke output without any change in arterial pressure during exercise indicates enhancement of cardiac betareceptor activity. At rest however, the increase in heart rate and cardiac output probably was partially a reflex response to the reduction in mean systemic arterial pressure. Several investigators ${ }^{16}$ have shown that the stimulation of beta-adrenergic activity produced by terbutaline, whether central or reflex in origin, is quantitatively less than that produced by other sympathomimetic amines when used in clinically effective doses. Despite this proviso, caution should be exercised in the use of these drugs in patients with associated ischaemic heart disease when an increase in cardiac work may upset the myocardial oxygen balance.

We used $250 \mu \mathrm{g}$ terbutaline intravenously as a bolus in the present studies. This dose was chosen because previous studies ${ }^{17}$ have shown that doses below this level do not produce any discernible haemodynamic effects. Furthermore, Nilsson et $a l^{18}$ have demonstrated that approximately the same serum levels are obtained 30 minutes after intravenous injection of $250 \mu \mathrm{g}$ and one to three hours after $5 \mathrm{mg}$ orally. Doses far in excess of $250 \mu \mathrm{g}$ have been used in patients with status asthmaticus without any untoward effects. ${ }^{19}$

Attention has been drawn to the possible adverse effect of beta-adrenergic agonists on the ventilation/perfusion relationship in patients with chronic pulmonary disease. ${ }^{6}$ In our studies we failed to show any increase in venous admixture although a slight but significant fall in systemic arterial blood oxygen tension was observed at rest. The increase in alveolar ventilation coupled with improvement in the mixed venous oxygen saturation probably offset any imbalance in the ventilation/perfusion relationship.

We thank Professor J van der Meer, Professor JP Roos, and Dr J Stam for encouragement and advice. Our thanks are also due to the nurses and technicians of the cardiac catheterisation unit and the pathophysiology department and, for secretarial assistance, to Ineke de BrouwerWester.

\section{References}

1 Harvey RM, Enson Y, Ferrer MI. A reconsideration of the origins of pulmonary hypertension.
Chest 1971; 59:82-94.

2 Harris P, Heath D. The human pulmonary circulation. Edinburgh: Churchill Livingstone, 1977.

3 Innes IR, Nickerson M. In: Goodman LS, Gilman A, eds. The pharmacological basis of therapeutics. Fifth edition. New York: Macmillan, 1975: 504.

4 Sackner MA, Dougherty R, Watson H, Wanner A. Hemodynamic effects of epinephrine and terbutaline in normal man. Chest 1975; 68:616-24.

5 Stockley RA, Finnegan P, Bishop JM. Effects of intravenous terbutaline on arterial blood gas tensions, ventilation and pulmonary circulation in patients with chronic bronchitis and cor pulmonale. Thorax 1977; 32:601-5.

6 Harris L. Comparison of cardiorespiratory effects of terbutaline and salbutamol aerosols in patients with reversible airways obstruction. Thorax 1973; 28:592-5.

7 Grossman W. Cardiac catheterisation and angiography. Philadelphia: Lea and Febiger, 1974: 329.

8 Sykes MK, McNicol MW, Campbell EJM. Respiratory failure. Second edition. Oxford: Blackwell Scientific Publications, 1976: 441-3.

9 Lockhart A, Tzareva M, Nader F, Leblanc P, Schrijen F, Sadoul P. Elevated pulmonary artery wedge pressure at rest and during exercise in chronic bronchitis: fact or fancy. Clin Sci 1969; 37:503-17.

10 Sancetta SM, Rakita L. Response of pulmonary artery pressure and total pulmonary resistance of untrained, convalescent man to prolonged mild steady state exercise. J Clin Invest 1957; 36: 1138-49.

11 Harris P, Segel N, Green I, Housley E. The influence of the airways resistance and alveolar pressure on the pulmonary vascular resistance in chronic bronchitis. Cardiovasc Res 1968; 2:84-92.

12 Editorial. The left ventricle in chronic bronchitis. Lancet 1971; 2:1019-20.

13 Kachel RG. Left ventricular function in chronic obstructive pulmonary disease. Chest 1978; 74: 286-90.

14 Ferrer MI, Enson Y, Kilcoyne MM, Harvey RM. Effects of isoproterenol on the pulmonary circulation in patients with chronic obstructive lung disease. Circulation 1971; 43:528-37.

15 Lockhart A, Lissac J, Salmon D, Zappocosta C, Benismail M. Effects of isoproterenol on the pulmonary circulation in obstructive airways disease. Clin Sci 1967; 32:177-87.

16 Arner B, Bertler A, Karlefors T, Westling H. Circulatory effects of orciprenaline, adrenaline and a new sympathomimetic beta receptor stimulating agent, terbutaline, in normal human subjects. Acta Med Scand 1970; 512 suppl: 25-32.

17 Arner B. A comparative clinical trial of different subcutaneous doses of terbutaline and orciprenaline in bronchial asthma. Acta Med Scand 1970; 512 suppl: $45-8$. 
18 Nilsson HT, Persson K, Tegner K. The metabolism of terbutaline in man. Xenobiotica 1972; 2:363-75.
19 Pang LM, Rodriguez-Martinez F, Davis $\mathrm{WJ} \overrightarrow{\vec{F}}$ Mellins RB. Terbutaline in the treatment of status asthmaticus. Chest 1977; 72:469-73. 